\title{
Proglucagon Products in Plasma of Noninsulin-dependent Diabetics and Nondiabetic Controls in the Fasting State and after Oral Glucose and Intravenous Arginine
}

\author{
Cathrine Orskov, ${ }^{*}$ Jorgen Jeppesen, ${ }^{*}$ Sten Madsbad, ${ }^{*}$ and Jens J. Holst \\ *Department of Clinical Biochemistry, Rigshospitalet, and ${ }^{\S}$ Institute of Medical Physiology C, Panum Institute, \\ University of Copenhagen, Copenhagen; and ${ }^{\ddagger}$ Department of Medicine F, Herlev Hospital, Herlev, Denmark
}

\begin{abstract}
We investigated the major products of proglucagon (PG) processing in plasma in the fasting state, after intravenous arginine and after an oral glucose load in noninsulin-dependent diabetics (NIDDM) and in weight matched controls using specific radioimmunoassays and analytical gel filtration. In the fasting state the glucagonlike peptide-1 (GLP-1) immunoreactivity was significantly elevated in the NIDDM group compared with the control group. Both after intravenous arginine and after an oral glucose load a rise in the plasma concentrations of all immunoreactive moieties measured was seen. All integrated incremental responses after intravenous arginine were identical in the two groups. After oral glucose the insulin concentrations in plasma were lower and the concentrations of all proglucagon products were higher in the NIDDM group compared to the control group. The gel filtration analysis showed that arginine stimulated the secretion of pancreatic glucagon (PG 33-61), major proglucagon fragment (PG 72-158) and probably GLP-1 (PG 72-107 amide) in both groups, whereas oral glucose stimulated the secretion of glicentin (PG 1-69) and intestinal GLP-1 (PG 78-107 amide), an insulinotropic hormone. The elevated levels of immunoreactive GLP-1 in diabetics in the fasting state were mainly due to an increased concentration of major proglucagon fragment. (J. Clin. Invest. 1991. 87:415-423.) Key words: glucagon • glucagonlike $\bullet$ peptide-1 $\bullet$ glicentin $\bullet$ oxyntomodulin • enteroglucagon
\end{abstract}

\section{Introduction}

In 1983 the structure of human proglucagon was deduced by Bell and co-workers from the nucleotide sequence of the glucagon gene (1). The 160-amino acid prohormone, proglucagon $(\mathrm{PG})^{1}$, has been shown to be processed differentially in the pancreas and the small intestine in man (2). In the pancreas the main products produced are (a) glucagon, $(b)$ a 30 -amino acid peptide glicentin-related pancreatic peptide (GRPP), and (c) a large peptide-designated major proglucagon fragment (MPGF) that contains two glucagonlike sequences $(3,4)$ (Fig. 1). The exact structure of MPGF is not known, but if the amino acid

Address correspondence to Dr. Cathrine Ørskov, Dept. of Clinical Biochemistry KK 3011, Rigshospitalet, Blegdamsvej 9, DK-2100 Copenhagen $\emptyset$, Denmark.

Received for publication 26 February 1990 and in revised form 30 August 1990.

J. Clin. Invest.

(c) The American Society for Clinical Investigation, Inc.

$0021-9738 / 91 / 02 / 0415 / 09 \$ 2.00$

Volume 87, February 1991, 415-423 composition of rat MPGF, which was determined by Patzelt et al., is compared with the rat proglucagon sequence it is most likely that MPGF corresponds to PG 72-158 in the rat (4). The only proglucagon derived pancreatic peptide with known biological activity is glucagon.

In the small intestine the main products of proglucagon are enteroglucagon (named glicentin in the pig [5]) which corresponds to PG 1-69 and thus includes the glucagon sequence, and two separate peptides, both showing great homology with glucagon: glucagonlike peptide-1 (GLP-1) which corresponds to PG 78-107 amide and glucagonlike peptide-2 (GLP-2) which corresponds to PG 126-158 (5-7). The major intestinal proglucagon product with known biological effect is GLP-1, which has been shown to be both potently insulinotropic and glucagonostatic (8-12).

Though much is known about the structure of the proglucagon products that can be extracted from pancreatic and intestinal tissues, little is known about the secreted proglucagon products in man and about stimuli for the secretion of these peptides.

To elucidate these questions, we studied the proglucagon products in plasma under three conditions: in the fasting state, after an oral glucose load, and after an intravenous arginine infusion (the glucose and the arginine load being known to stimulate the secretion of intestinal and pancreatic proglucagon products, respectively, in pigs) (12). Furthermore, the study was carried out both in noninsulin-dependent diabetics and in weight-matched controls to investigate whether disturbances in the glucose metabolism might influence the secretion of proglucagon products in man.

To be able to identify the proglucagon products in plasma we used two methods: $(a)$ radioimmunoassays, using both an antiserum directed against the carboxy-terminus of pancreatic glucagon (4305) and an antiserum which cross-reacts with equal strength with all peptides containing the glucagon sequence regardless of $\mathrm{NH}_{2}$ - or $\mathrm{COOH}$-terminal extensions (4304) (a so-called processing-independent antiserum) for glucagon measurements, and using an antiserum for GLP-1 measurements which cross-reacts with equal strength with all peptides containing the GLP-1 sequence regardless of $\mathrm{NH}_{2}$ - or $\mathrm{COOH}$-terminal extensions; and $(b)$ gel filtration analysis. Because processing-independent antisera have the virtue as well as the disadvantage of measuring all molecular forms containing the amino acid sequence against which the antiserum was raised, gel filtration was a necessary supplement to determine the molecular nature of the peptides measured.

1. Abbreviations used in this paper: GLP-1, glucagonlike peptide-1; GRPP, glicentin-related pancreatic peptide; MPGF, major proglucagon fragment; NIDDM, noninsulin-dependent diabetic; PG, proglucagon. 


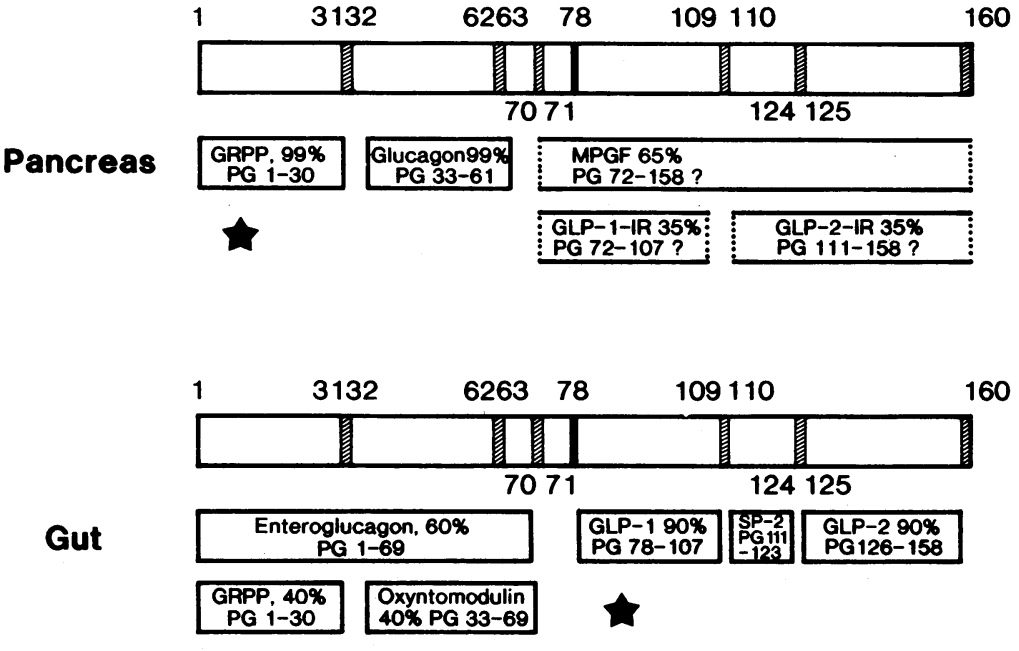

Figure 1. Proglucagon processing in human pancreas and small intestine. Solid boxes indicate known structures; peptides with incompletely characterized structures are indicated as hatched boxes. The relative amount of a given peptide sequence occurring in each organ is indicated in percent of the total amount of proglucagon processed. In the pancreas the main products are glucagon, GRPP, and MPGF. Smaller amounts of not fully characterized glucagonlike peptide- 1 and -2 (GLP-1 and GLP-2) immunoreactivities are found. *Very small amounts $(\sim 1 \%)$ of PG 1-61 and PG 1-69 are formed in the pancreas. In the small intestine the main products are GLP-1, GLP-2, glicentin, oxyntomodulin, and GRPP. *A small amount $(<10 \%)$ of the total GLP-1-like immunoreactivity probably corresponds to MPGF.
For the two additional intestinal products of proglucagon, intervening peptide- 2 and glucagonlike peptide- 2 no biological activity has been discovered so far (7) and none of the peptides influence the secretion from the endocrine pancreas (unpublished studies). Analyses for these peptides were therefore not included in the present study.

\section{Methods}

Eight noninsulin-dependent diabetics (NIDDM) and eight weightmatched nondiabetic controls were studied. The diagnosis NIDDM was based on World Health Organization criteria: venous fasting blood glucose $>6.7 \mathrm{mmol} /$ liter and/or venous blood glucose $120 \mathrm{~min}$ after a $75-\mathrm{g}$ oral glucose load at or above $10.0 \mathrm{mmol} / \mathrm{liter}$. All diabetics were treated with diet alone; none used oral hypoglycemic drugs or received other medication. None of the diabetics showed signs of autonomic or peripheral neuropathy. All diabetics had normal serum creatinine and none had albuminuria. Six patients had no retinopathy, two had mild retinopathy. The average duration of diabetes was $18 \pm 7 \mathrm{mo}$. (Table I). The study was approved by the local ethical committee, and all participants agreed to participate after the nature and possible risks of the study had been explained to them.

The experiments were carried out after an overnight fast $(>8 \mathrm{~h}$ ) on two different days. Polyethylene cannulas (Venflon, Viggo Products, Helsingborg, Sweden) were inserted into antecubital veins for blood sampling and arginine infusion and kept patent with saline.

Oral glucose load. $100 \mathrm{~g}$ of glucose dissolved in 0.5 liters of water was ingested within $5 \mathrm{~min}$. Blood was sampled at $-15,0,30,60,90$, 120,150 , and $180 \mathrm{~min}$ after the glucose ingestion into tubes containing EDTA, ethylenedinitrilo tetraacetic acid, $6 \mathrm{mmol} /$ liter (E. Merck, Darmstadt, FRG) and aprotinin, 500,000 KIE/liter (Trasylol, Bayer, AG, Leverkusen, FRG) and kept on ice until centrifugation at $4^{\circ} \mathrm{C}$ (within $0.5 \mathrm{~h}$ ). Plasma samples were stored at $-20^{\circ} \mathrm{C}$ until assay. Aliquots of the blood samples were stored for later glucose determination by the glucose oxidase method. At $120 \mathrm{~min}$, blood corresponding to 20 $\mathrm{ml}$ of plasma was drawn from each subject for later chromatography.

Intravenous arginine infusion. $0.5 \mathrm{~g} / \mathrm{kg}$ body weight of arginine- $\mathrm{HCl}$ (Ajinomoto Co., Tokyo, Japan) dissolved in sterile water $(1 \mathrm{~g} / 10 \mathrm{ml}$ ) was infused intravenously in the course of $30 \mathrm{~min}$. Blood was sampled at $-15,0,15,30,45$, and $60 \mathrm{~min}$ after start of the arginine infusion, centrifuged, and stored at $-20^{\circ} \mathrm{C}$ until assay. At -15 and +30 min, blood corresponding to $20 \mathrm{ml}$ of plasma was drawn from each subject for later chromatography.

Radioimmunoassays. Pancreatic glucagon was measured using antiserum 4305, monoiodinated ${ }^{125}$ I-labeled glucagon (generous gift from Novo Research Institute, Bagsværd, Denmark) and highly purified porcine glucagon (Novo Research Institute) as described $(14,15)$. Antiserum 4305 recognizes the $\mathrm{COOH}$-terminus of glucagon and thus cross-reacts with all peptides with the same $\mathrm{COOH}$-terminus as pancreatic glucagon. The experimental detection limit was below 2 pmol/ liter. Total glucagon immunoreactivity (IR) was measured using the antiserum 4304 , monoiodinated ${ }^{125}$ I-labeled glucagon and highly purified porcine glucagon as described $(14,15)$. Antiserum 4304 crossreacts with equal strength with all peptides that contain the glucagon sequence, regardless of the presence or absence of $\mathrm{COOH}$ - or $\mathrm{NH}_{2}$-terminal extensions. The experimental detection limit was $<2$ pmol/liter. None of the glucagon antisera cross-reacted with GLP- 1 or any other members of the glucagon/secretin family of peptides. The intraassay coefficient of variation in plasma was $<6 \%$, and the interassay coefficient of variation was $<15 \%$ for both glucagon assays.

Glucagonlike peptide-1 immunoreactivity was measured using synthetic GLP-1 (PG 78-107 amide, code 7168, Peninsula, Laboratories, Inc., St. Helens, Merseyside, UK) for standards, antiserum 2135 (final dilution, 1:150,000) and ${ }^{125}$ I-labeled synthetic GLP-1 (as above) iodinated by the stoichiometric chloramine-T method as described in (16)

Table I. Data on Eight NIDDM Patients (N) and Eight Weight-matched Control Subjects (C)

\begin{tabular}{|c|c|c|c|c|c|}
\hline & Sex & Age & $\begin{array}{c}\text { Body } \\
\text { mass index } \\
(B M I)\end{array}$ & $\begin{array}{c}\text { Known duration } \\
\text { of diabetes }\end{array}$ & Treatment \\
\hline & & $y r$ & & $m s$ & \\
\hline$N_{1}$ & $\mathbf{M}$ & 63 & 23.9 & 60 & Diet \\
\hline $\mathrm{N}_{2}$ & $\mathbf{F}$ & 50 & 32.7 & 1 & Diet \\
\hline $\mathrm{N}_{3}$ & $\mathbf{M}$ & 42 & 28.7 & 24 & Diet \\
\hline $\mathrm{N}_{4}$ & $\mathbf{M}$ & 73 & 26.4 & 4 & Diet \\
\hline $\mathrm{N}_{5}$ & $\mathbf{M}$ & 54 & 23.6 & 26 & Diet \\
\hline $\mathrm{N}_{6}$ & $\mathbf{M}$ & 65 & 31.1 & 24 & Diet \\
\hline $\mathrm{N}_{7}$ & $\mathbf{M}$ & 56 & 31.4 & 4 & Diet \\
\hline $\mathrm{N}_{8}$ & $\mathbf{M}$ & 68 & 27.8 & 1 & Diet \\
\hline$C_{1}$ & $\mathbf{M}$ & 40 & 29.4 & - & - \\
\hline $\mathrm{C}_{2}$ & $\mathbf{M}$ & 42 & 25.1 & - & - \\
\hline $\mathrm{C}_{3}$ & $\mathbf{M}$ & 50 & 28.1 & - & - \\
\hline $\mathrm{C}_{4}$ & $\mathbf{M}$ & 56 & 29.4 & - & - \\
\hline $\mathrm{C}_{5}$ & $\mathbf{M}$ & 54 & 29.0 & - & - \\
\hline $\mathrm{C}_{6}$ & $\mathbf{M}$ & 46 & 28.6 & - & - \\
\hline$C_{7}$ & $\mathbf{M}$ & 41 & 25.4 & - & - \\
\hline $\mathrm{C}_{8}$ & $\mathbf{F}$ & 53 & 33.6 & - & - \\
\hline
\end{tabular}


and purified by reverse phase high pressure liquid chromatography on a Vydac C-18 column (Separations Group Ltd., London, UK), using a 100 -min $30-50 \%$ gradient of acetonitrile in water (Grade S, Rathburn Chemicals Ltd., Walkerburn, Scotland) containing in addition $0.1 \%$ TFA (Pierce Chemical Co., Rockford, IL). Antiserum 2135 cross-reacts with equal strength with all peptides containing the GLP-1 sequence regardless of $\mathrm{NH}_{2}$ - or $\mathrm{COOH}$-terminal extensions. The antiserum against GLP-1 did not show any cross-reactivity with glucagon, GLP-2 or any other members of the glucagon/secretin family of peptides. The experimental detection limit in plasma was $<5 \mathrm{pmol} /$ liter. The intraassay coefficient of variation was $<8 \%$; the interassay coefficient of variation was $<16 \%$. Insulin was measured using antiserum 2004 , which cross-reacts $100 \%$ with human insulin, monoiodinated ${ }^{125}$ I (Tyr A 14) labeled porcine insulin (generous gift Novo Research Institute) and purified porcine insulin (Novo Research Institute) as described in reference 17.

Before all plasma measurements, $700 \mu \mathrm{l}$ plasma/sample/assay were extracted in $70 \%$ ethanol ( $\mathrm{vol} / \mathrm{vol}$, final concentration), the supernatant was dried down using a vacuum centrifuge (Heto, Hillerød, Denmark) and redissolved in veronal buffer ( $20 \mathrm{mmol} / \mathrm{liter}, \mathrm{pH} \mathrm{8.4})$, containing in addition 0.1\% BSA (A-7034, Sigma Chemical Co., St. Louis, MO) and thiomersal $0.6 \mathrm{mmol} /$ liter. All plasma samples were assayed in duplicate. The recovery of pancreatic glucagon, GLP-1, and insulin added to plasma before extraction were $70 \pm 8 \%, 75 \pm 8 \%$, and $75 \pm 6 \%$, respectively.

For the plasma measurements and for measurements of eluate from the gel filtrations of Seppak concentrated plasma, $300 \mu \mathrm{l}$ of sample and $100 \mu \mathrm{l}$ of diluted antiserum were preincubated for $24 \mathrm{~h}$ followed by $24 \mathrm{~h}$ of incubation with $100 \mu \mathrm{l}$ of labeled peptide $(\sim 10 \mathrm{fmol})$. For the measurement of GLP-1 immunoreactivity in the fractions eluted from the gel filtrations of crude plasma, the incubation volume was increased to $750 \mu \mathrm{l}$ and the incubation time increased to $48 \mathrm{~h}$ of preincubation plus $48 \mathrm{~h}$ of incubation with labeled GLP-1, to increase sensitivity of the assay. The experimental detection limit employing this procedure was between 1 and $2 \mathrm{pmol} / \mathrm{liter}$. In all assays the free and bound moieties were separated by plasma-coated charcoal (E. Merck, Darmstadt, FRG).

Chromatography. 20-ml plasma samples from each subject, drawn at the times $-15,30 \mathrm{~min}$ after initiation of the arginine infusion and $120 \mathrm{~min}$ after oral glucose, were loaded separately and slowly onto Seppak cartridges and activated according to the manufacturer's description (Waters Associates, Milford, MA). The cartridges were then washed with $10 \mathrm{ml}$ of water containing in addition $0.2 \%$ of TFA, and then with $5 \mathrm{ml}$ of $20 \%$ acetonitrile in water. Finally, they were eluted first with $4 \mathrm{ml}$ of $45 \%$ acetonitrile in water and thereafter with $5 \mathrm{ml}$ of pure acetonitrile. All eluant solutions contained in addition $0.2 \%$ of TFA. All fractions eluted with $45 \%$ acetonitrile were collected and evaporated in a vacuum centrifuge (Heto, Roskilde, Denmark), reconstituted in $4 \mathrm{ml}$ of veronal buffer (as above) and applied onto a $16 \times 1,000$ mm column (XK 16/100, Pharmacia Fine Chemicals, Uppsala, Sweden) packed with Sephadex G50 SF (Pharmacia Fine Chemicals) in veronal buffer (as above). Total glucagon and GLP-1 immunoreactivity were measured in all fractions eluted from the Seppak cartridges. Furthermore, plasma samples of $\sim 4 \mathrm{ml}$ from NIDDM patients and control subjects drawn in the fasting state $(n=3), 120$ min after the glucose load $(n=3)$ and $30 \mathrm{~min}$ after initiation of the arginine infusion $(n=3)$ were applied directly onto the same column and eluted as above for comparison.

Before gel filtrations, trace amounts of ${ }^{125} \mathrm{I}$ albumin and ${ }^{22} \mathrm{NaCl}$ were added to all samples for internal calibration. Column flow was $0.25 \mathrm{ml} / \mathrm{min}$. Effluent fractions of $1.5 \mathrm{ml}$ were collected every $6 \mathrm{~min}$ and assayed for total glucagon and GLP-1 immunoreactivity as described above. The void volume $\left(V_{\mathrm{o}}\right)$ was determined as the elution volume of ${ }^{125}$ I albumin. The available inner volume $\left(V_{\mathrm{i}}\right)$ of the gel bed was determined as the difference between the elution volumes of ${ }^{125} I$ albumin and ${ }^{22} \mathrm{NaCl}$. The coefficient of distribution $\left(K_{\mathrm{d}}\right)$ was calculated for all eluted immunoreactive moieties using the formula $K_{\mathrm{d}}=\left(V_{\mathrm{e}}\right.$ $\left.-V_{\mathrm{o}}\right) / V_{\mathrm{i}}$, where $V_{\mathrm{e}}$ was the elution volume of the peak in question. The results of the gel filtrations are both depicted as fractional output (defined as the fraction of the total amount of immunoreactivity eluted from that column measured at the $K_{\mathrm{d}}$ interval indicated) of the peptide in question plotted against $K_{\mathrm{d}}$, calculated as above, and as vertical bars showing in absolute values the concentrations in plasma of each of the immunoreactive peaks identified by gel filtration (Figs. 4-6). The column was calibrated with the following peptides: GLP-1 (PG 78-107 amide, code 7168, Peninsula), GLP-1 (PG 72-107 amide, code 7166, Peninsula), porcine glucagon (Novo Research Institute) oxyntomodulin (PG 33-69, code 7170, Peninsula), and porcine glicentin (PG 1-69), produced in our own laboratory.

The recoveries of synthetic GLP-1 (PG 78-107 amide) and glucagon were investigated by applying a known amount of the peptides to $20 \mathrm{ml}$ of plasma, submitting the mixture to Seppak concentration and subsequent gel filtration as above. $20 \mathrm{ml}$ of the same plasma without addition of peptide were concentrated and subjected to gel filtrated as above to allow a correction for the endogenous peptides present in plasma. To investigate the recovery of the major proglucagon fragment, a known amount of pig MPGF was added to $26 \mathrm{ml}$ of plasma. 5 $\mathrm{ml}$ were added directly to the gel filtration column, while $20 \mathrm{ml}$ were concentrated by Seppak and then applied to the gel filtration column. 1 $\mathrm{ml}$ was extracted in $70 \%$ ethanol as described above. All fractions were then assayed for GLP-1 immunoreactivity (Fig. 7). The major proglucagon fragment was obtained from gel filtrations of pig pancreas (13) and purified by HPLC before the recovery experiments. The recoveries of the endogenous peptides subjected to Seppak concentration and gel filtration were estimated by comparing the amount of peptide eluted from the gel filtration column and the amount applied to the Seppak cartridges as measured in plasma after ethanol extraction, but corrected for the recovery inherent in the ethanol extraction procedure (see above) $(16,18)$. Because all determinations of GLP-1 concentrations in plasma were made after ethanol extraction, we also studied the gel filtration profiles of GLP-1 immunoreactive material from a pool of plasma, drawn from the NIDDM patients after the intravenous arginine infusion, both with and without extraction with $70 \%$ ethanol.

Statistics. All measured values are presented as mean \pm SEM for $n$ $=8$, unless otherwise stated. The significance of differences was estimated by Mann Whitney's U-test for unpaired data. Differences resulting in $P$ values of 0.05 or less were considered significant. Integrated incremental responses were calculated by trapezoid integration. Friedman's two-way analysis of variance was employed for evaluation of changes as function of time.

\section{Results}

Peptide concentrations in plasma. After the intravenous arginine infusion rapid and significant increases were measured in insulin concentration, pancreatic glucagon concentration, total glucagon immunoreactivity, and GLP-1 immunoreactivity, that reached a maximum 30 min after initiation of the arginine infusion (Fig. 2). Basal levels of GLP-1 immunoreactivity as well as GLP-1-immunoreactivity at 30,45 , and $60 \mathrm{~min}$ were significantly higher in the NIDDM group compared with the control group, but the integrated incremental GLP-1 responses were similar (Table II). No significant differences between the NIDDM group and the control group were observed for any of the other peptide responses to arginine. By regression analysis we found a significant correlation between the integrated, incremental GLP-1 response and the integrated, incremental total glucagon response $(r=0.79, P<0.001)$ (not shown).

Fasting blood glucose levels were significantly higher in the NIDDM group compared to the control group $(9.9 \pm 1.1$ vs. $5.4 \pm 0.1 \mathrm{mmol} /$ liter). A significantly larger integrated, incremental blood glucose response was observed in the NIDDM group in response to the arginine infusion compared with the control group $(P=0.014$, Table II). 


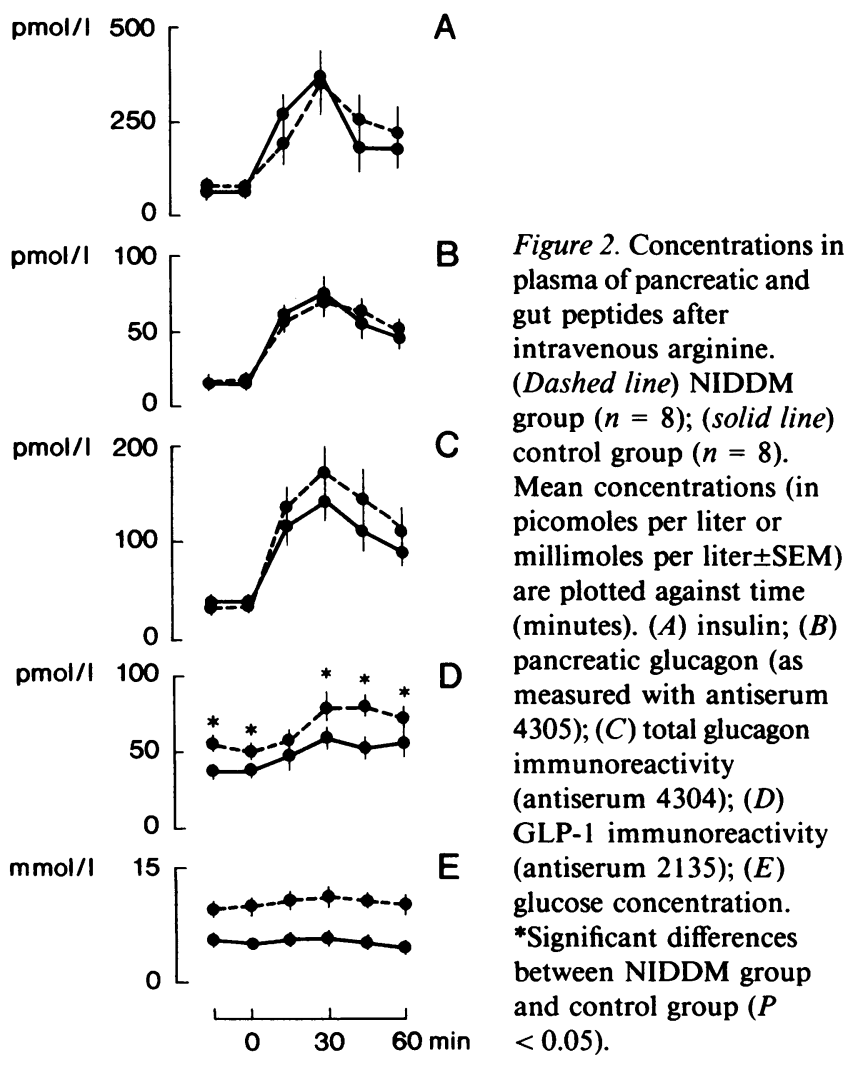

After the oral glucose load (Fig. 3) an increase in insulin concentration was observed both in the NIDDM group and in the control group. The basal levels of insulin were similar in the two groups. In the control group a maximum was reached at 90 min $(599 \pm 166 \mathrm{pmol} / \mathrm{liter})$, whereas the insulin concentration in the NIDDM group did not increase further $30 \mathrm{~min}$ after the glucose load and remained unchanged until $150 \mathrm{~min}(140 \pm 44$ $\mathrm{pmol} / \mathrm{liter}$ at $30 \mathrm{~min})$. The integrated incremental insulin response in the control group was significantly higher than in the NIDDM group (Table II $[P=0.005]$ ). Total glucagon immunoreactivity in the NIDDM group increased from $35 \pm 4 \mathrm{pmol} /$ liter to a maximum of $58 \pm 7 \mathrm{pmol} / \mathrm{liter}$ at $60 \mathrm{~min}$ after the glucose load, whereas in the control group a significantly smaller increase in total glucagon immunoreactivity (from $31.7 \pm 2.4 \mathrm{pmol} / \mathrm{liter}$ to a mean value in the $30-120$-min period of $36.0 \pm 2.5 \mathrm{pmol} /$ liter) was observed (Fig. 3). The increase was significant $(P<0.05$, one-tailed Wilcoxon test). The integrated incremental total glucagon response was significantly higher in the NIDDM group compared to the control group $(P=0.04$, Table II). The basal levels of GLP-1 immunoreactivity in the NIDDM group were significantly higher than in the control group ( $47 \pm 7$ vs. $37 \pm 3$ pmol/liter). A significant increase in GLP-1 immunoreactivity was found in both groups, with a maximum at $30 \mathrm{~min}$ after the glucose load, followed by a slow decrease towards basal levels (Fig. 3). The GLP-1 concentrations measured at 30,60, and $90 \mathrm{~min}$ after the glucose load were significantly higher in the NIDDM group, and the integrated incremental GLP-1 responses were also significantly higher in the NIDDM group compared to the control group (Table II, $P=0.014$ ). By regression analysis we found a significant correlation between the integrated incremental GLP-1 re-
Table II. Comparison of Integrated Incremental Hormone Responses to Oral Glucose and to Intravenous Arginine (mean $\pm S E M, n=8$ )

\begin{tabular}{|c|c|c|c|}
\hline & NIDDM & Control group & $\begin{array}{c}P \text { values, } \\
\text { NIDDM } \\
\text { vs. controls }\end{array}$ \\
\hline \multicolumn{4}{|l|}{ Intravenous arginine } \\
\hline $\begin{array}{l}\text { Insulin } \\
\quad(\mathrm{pmol} / \mathrm{l} \mathrm{min})\end{array}$ & $9511 \pm 2640$ & $10629 \pm 2386$ & NS \\
\hline $\begin{array}{l}\text { Pancreatic glucagon } \\
(\mathrm{pmol} / \mathrm{lmin})\end{array}$ & $2458 \pm 348$ & $2427 \pm 340$ & NS \\
\hline $\begin{array}{l}\text { Total glucagon } \\
(\mathrm{pmol} / \mathrm{l} \mathrm{min})\end{array}$ & $6192 \pm 1490$ & $4237 \pm 730$ & NS \\
\hline $\begin{array}{l}\text { GLP-1 } \\
\qquad(\mathrm{pmol} / \mathrm{l} \mathrm{min})\end{array}$ & $1054 \pm 348$ & $989 \pm 240$ & NS \\
\hline $\begin{array}{l}\text { Glucose } \\
\qquad(\mathrm{mmol} / \mathrm{l} \mathrm{min})\end{array}$ & $42 \pm 9$ & $2.4 \pm 9.5$ & 0.014 \\
\hline $\begin{array}{l}\text { Oral glucose } \\
\text { Insulin }\end{array}$ & & & \\
\hline$(\mathrm{pmol} / \mathrm{l} \mathrm{min})$ & $8588 \pm 4634$ & $48248 \pm 13422$ & 0.005 \\
\hline $\begin{array}{l}\text { Pancreatic glucagon } \\
(\mathrm{pmol} / \mathrm{lmin})\end{array}$ & $-158 \pm 75$ & $-611 \pm 168$ & 0.014 \\
\hline $\begin{array}{l}\text { Total glucagon } \\
(\mathrm{pmol} / \mathrm{l} \mathrm{min})\end{array}$ & $2579 \pm 1027$ & $392 \pm 262$ & 0.04 \\
\hline $\begin{array}{l}\text { GLP-1 } \\
\quad(p m o l / l \text { min })\end{array}$ & $5776 \pm 1674$ & $2015 \pm 644$ & 0.014 \\
\hline $\begin{array}{l}\text { Glucose } \\
\qquad(\mathrm{mmol} / \mathrm{lmin})\end{array}$ & $1081 \pm 214$ & $189 \pm 76$ & $<0.001$ \\
\hline
\end{tabular}

sponse and the integrated incremental total glucagon response $(r=0.89, P<0.001)$ (not shown).

The basal pancreatic glucagon concentrations were similar in the two groups. In the NIDDM group a slight decrease in pancreatic glucagon concentrations was found after the oral glucose load, whereas in the control group a larger decrease was

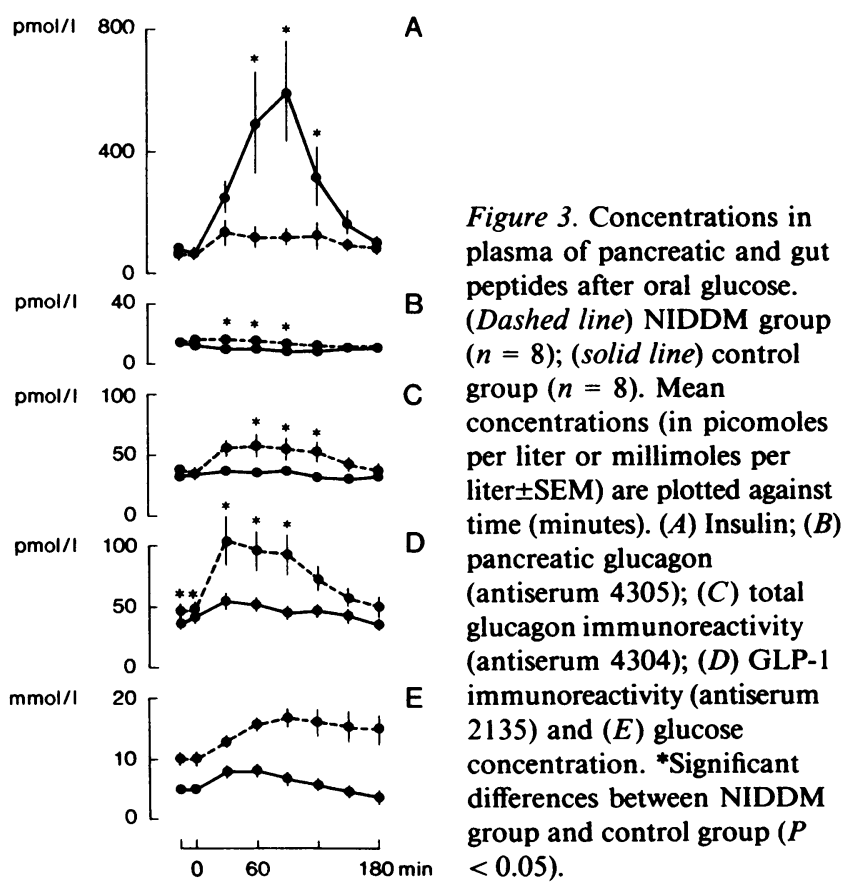


seen. The difference between the two groups was significant at the times 30,60, and $90 \mathrm{~min}$ after the glucose load. The integrated decremental glucagon responses were significantly smaller in the NIDDM group compared to the control group $(P$ 0.014 , Table II).

Blood glucose levels in the fasting state were significantly higher in the NIDDM group than in the control group, as expected. After the glucose load a rise in blood glucose was observed in the control group reaching a plateau after 30-60 min $(8.1 \pm 1.0 \mathrm{mmol} /$ liter $)$ followed by a rapid decrease to normal levels at $120 \mathrm{~min}$. In the NIDDM group the increase in blood glucose reached a maximum at $90 \mathrm{~min}(17.1 \pm 1.5 \mathrm{mmol} / \mathrm{liter})$ and was followed by a slow decrease. The integrated incremental glucose response was significantly higher in the NIDDM group compared to the control group ( $P<0.001$, Table II).

Gel filtration profiles of total immunoreactive glucagon (Fig. 4). By gel filtration of Seppak-concentrated fasting plasma from both the NIDDM patients and the controls two distinct immunoreactive peaks were identified with antiserum 4304: most of the immunoreactivity (see Fig. 4) eluted at $K_{d} 0.30$ corresponding to the elution position of (porcine) glicentin; the remaining immunoreactivity eluted at $K_{d} 0.75$. The position the latter indicates that it may consist of either or both glucagon and oxyntomodulin, as the glucagon marker elutes at $K_{\mathrm{d}}$ 0.80 and the oxyntomodulin marker elutes at $K_{d} 0.75$. The recovery of endogenous total glucagon immunoreactivity after gel filtration analysis of fasting plasma was $58 \pm 7$ and $79 \pm 10 \%$ in the NIDDM group and the control group, respectively (no significant difference in recovery (NS); $P=0.076$ ). The mean amount of total glucagon immunoreactivity eluting at $K_{d} 0.30$ (expressed as femtomoles per milliliter plasma applied to column) was significantly higher in the control group than in the NIDDM group, whereas the mean amount of total glucagon immunoreactivities eluting at $K_{d} 0.75$ were similar in the two groups (Fig. 4).

By gel filtration of Seppak-concentrated plasma drawn after the arginine infusion, both the distribution of molecular forms and the absolute amounts measured were indistinguishable in the NIDDM group and the control group. Two peaks were identified; a small peak eluting at $K_{\mathrm{d}} \mathbf{0 . 3 0}$ and a larger peak eluting at $K_{d} 0.80$, coeluting with the glucagon marker. The recovery of endogenous total glucagon immunoreactivity after gel filtration of plasma drawn after intravenous arginine was $47 \pm 5$ and $50 \pm 7 \%$ in the NIDDM group and the control group, respectively (NS, $P=0.478$ ). The mean amount of total glucagon immunoreactivity (expressed in femtomoles per milliliter plasma applied to column), eluting in either of the two immunoreactive peaks were similar in the two groups (Fig. 4).

By gel filtration of plasma drawn after the oral glucose, two immunoreactive peaks were identified: one large peak eluting at $K_{\mathrm{d}} 0.30$ and a very small peak eluting at $K_{\mathrm{d}} 0.75$, indicating that the latter peak might consist of either glucagon or oxyntomodulin. The recovery of total glucagon immunoreactivity after gel filtration of plasma drawn after the oral glucose was $87 \pm 4$ and $85 \pm 17 \%$ in the NIDDM group and the control group, respectively (NS, $P=0.478$ ). The mean amount of total glucagon immunoreactivity eluting both at $K_{d} 0.30$ and 0.75 were significantly higher in the NIDDM group than in the control group (Fig. 4).

Gel filtration profiles of GLP-1 immunoreactivity (Fig. 5). By gel filtration of concentrated fasting plasma two rather broad immunoreactive peaks were identified both in the
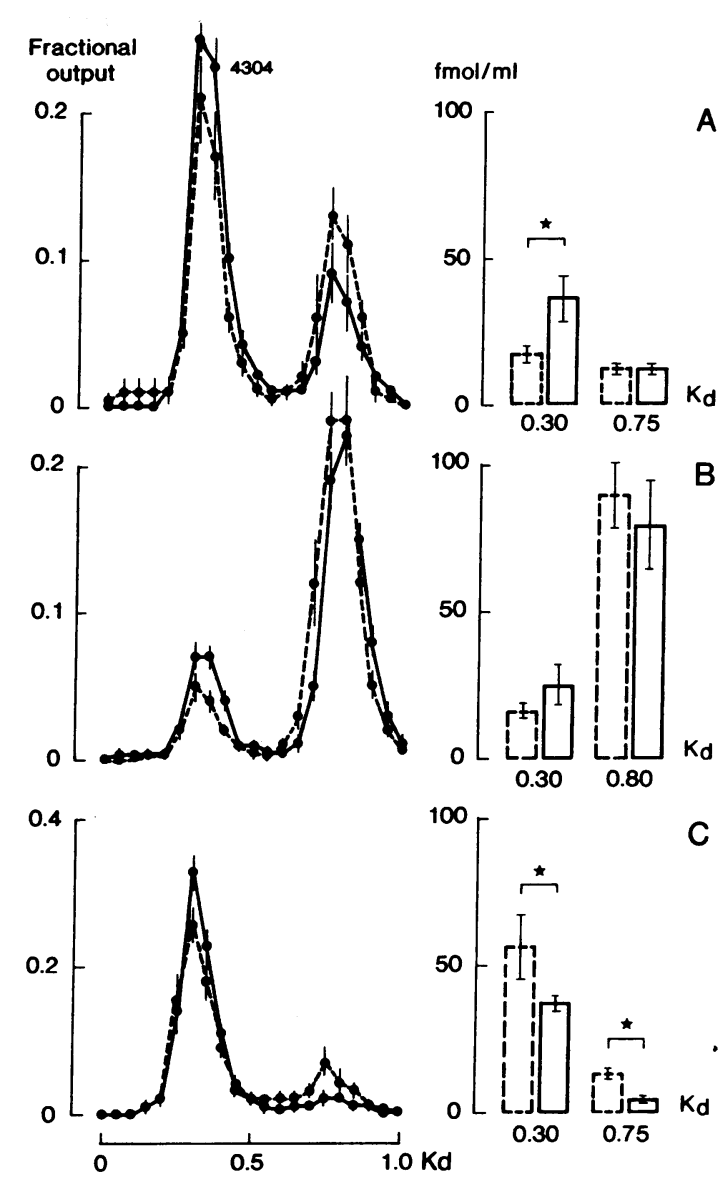

Figure 4. Gel filtration profiles of total glucagon immunoreactivity in plasma concentrated with Seppak. The figure shows the fractional and the absolute outputs (expressed in femtomoles per milliliter plasma) of total glucagon immunoreactivity, as measured with antiserum 4304 , in the fasting state $(A)$, after intravenous arginine $(B)$, and after oral glucose $(C)$. (Dashed line) NIDDM group $(n=8)$, (solid line) control group $(n=8)$. Left panels show the mean fractional outputs \pm SEM (defined as the fraction of the total amount of immunoreactivity eluted from each column at each $K_{d}$ interval) plotted against the coefficient of distribution, $K_{\mathrm{d}}$ (see Methods description). Vertical bars to the right show total glucagon immunoreactivity \pm SEM (femtomoles per milliliter applied plasma) in each major immunoreactive moiety identified by the gel filtration. *Significant differences between NIDDM group and control group $(P$ $<0.05)$.

NIDDM group and in the control group: a smaller peak (constituting $\sim 40 \%$ of the immunoreactivity measured) with maximum at $K_{\mathrm{d}} 0.15$ and a larger peak at $K_{\mathrm{d}} 0.55$, corresponding to the elution position of synthetic GLP-1 (PG 72-107 amide). The recovery of endogenous GLP-1 immunoreactivity after gel filtration was significantly lower in the NIDDM group compared to the control group $(27 \pm 5$ vs. $62 \pm 10 \%, P=0.02)$. The mean amount of GLP-1 immunoreactivity eluting at $K_{\mathrm{d}} 0.15$ (expressed in femtomoles per milliliter plasma applied to the column) was significantly higher in the control group than in the NIDDM group, whereas the mean amount of GLP-1 immunoreactivity eluting at $K_{\mathrm{d}} 0.55$ was similar in the two groups (Fig. 5).

By gel filtration of concentrated plasma drawn after the arginine infusion, two immunoreactive peaks were identified: a peak eluting at $K_{\mathrm{d}} 0.15$ (constituting $\sim 35 \%$ of the total 

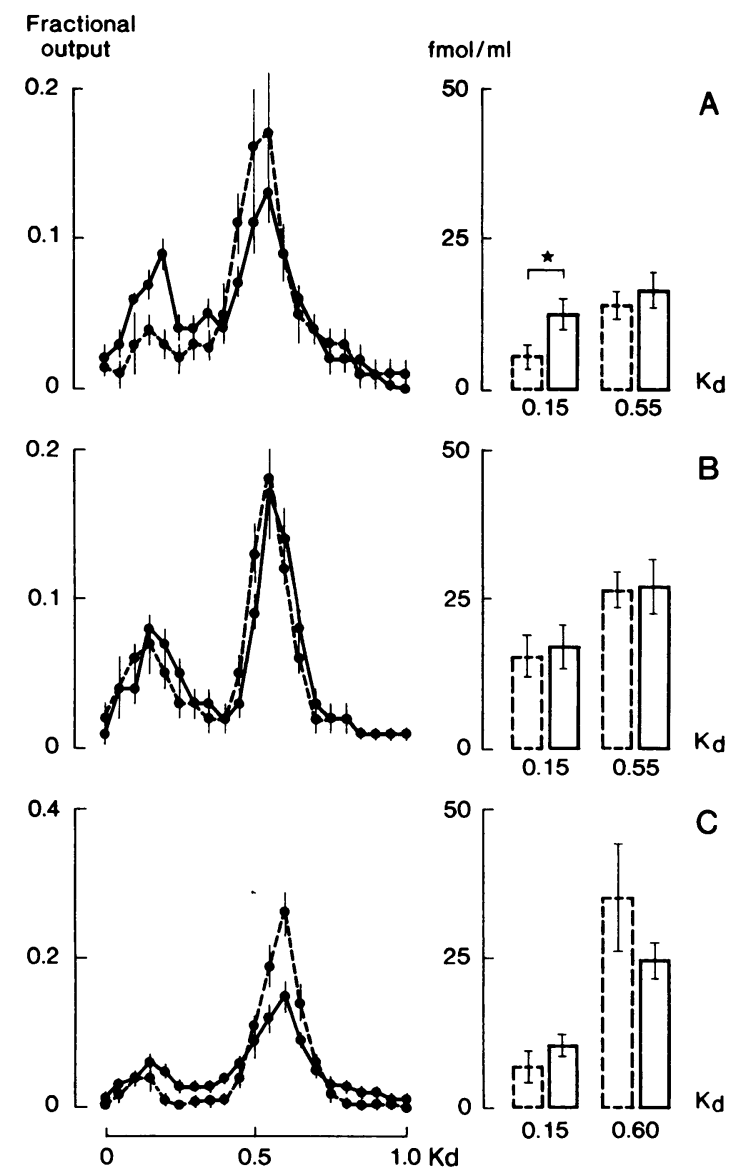

Figure 5. Gel filtration profiles of GLP-1 immunoreactivity in plasma concentrated with Seppak. The figure shows the fractional and the absolute outputs (in femtomoles per milliliter plasma) of GLP-1 immunoreactivity, as measured with antiserum 2135 , in the fasting state $(A)$, after intravenous arginine $(B)$, and after oral glucose $(C)$. (Dashed line) NIDDM group $(n=8)$, (solid line) control group ( $n$ $=8$ ). Left panels show the mean fractional outputs \pm SEM, defined as the fraction of the total amount of immunoreactivity eluted from each column at each $K_{\mathrm{d}}$ interval plotted against the coefficient of distribution, $K_{d}$ (see Methods description). The columns to the right show the GLP-1 immunoreactivity (femtomoles per milliliter applied plasma) in each major immunoreactive moiety identified by the gel filtration. *Significant differences between NIDDM group and control group $(P<0.05)$.

amount of immunoreactivity) and a larger peak at $K_{d} 0.55$. The recovery of GLP-1 immunoreactivity after gel filtration was lower in the NIDDM group compared to the control group $(40 \pm 9$ vs. $69 \pm 9 \%(P=0.06)$. The mean amount of GLP-1 immunoreactivity (expressed in femtomoles per milliliter applied plasma) eluting at $K_{\mathrm{d}} 0.15$ and $K_{\mathrm{d}} 0.55$ were similar in the two groups (Fig. 5).

In plasma sampled after oral glucose two immunoreactive peaks were measured in both the NIDDM group and in the control group. The elution positions of the two peaks were identical in the two groups: a smaller peak at $K_{d} 0.15-0.20$ and a larger peak at $K_{d} 0.60$, the latter coeluting with synthetic GLP-1 (PG 78-107 amide). However, both the fractional and the absolute amounts of GLP-1 immunoreactive material measured at $K_{\mathrm{d}} 0.60$ tended to be larger in the NIDDM group
$(P=0.14)$. The recovery of endogenous GLP- 1 immunoreactivity after gel filtration was significantly lower in the NIDDM group compared to the control group ( $38 \pm 10$ vs. $59 \pm 9 \%, P$ $=0.036$ ). The mean amounts of GLP-1 immunoreactivity (in femtomoles per milliliter applied plasma) eluting at $K_{d} 0.15$ were similar in the two groups (Fig. 5).

The recovery of synthetic GLP-1 (PG 78-107 amide) after Seppak concentration and subsequent gel filtration was $76 \pm 8 \%$. The recovery of exogenous glucagon after Seppak concentration and gelfiltration was $55 \pm 6 \%$. The recovery of porcine MPGF after Seppak concentration and gel filtration was $36 \%$ (Fig. 6). The recovery of porcine MPGF, mixed with

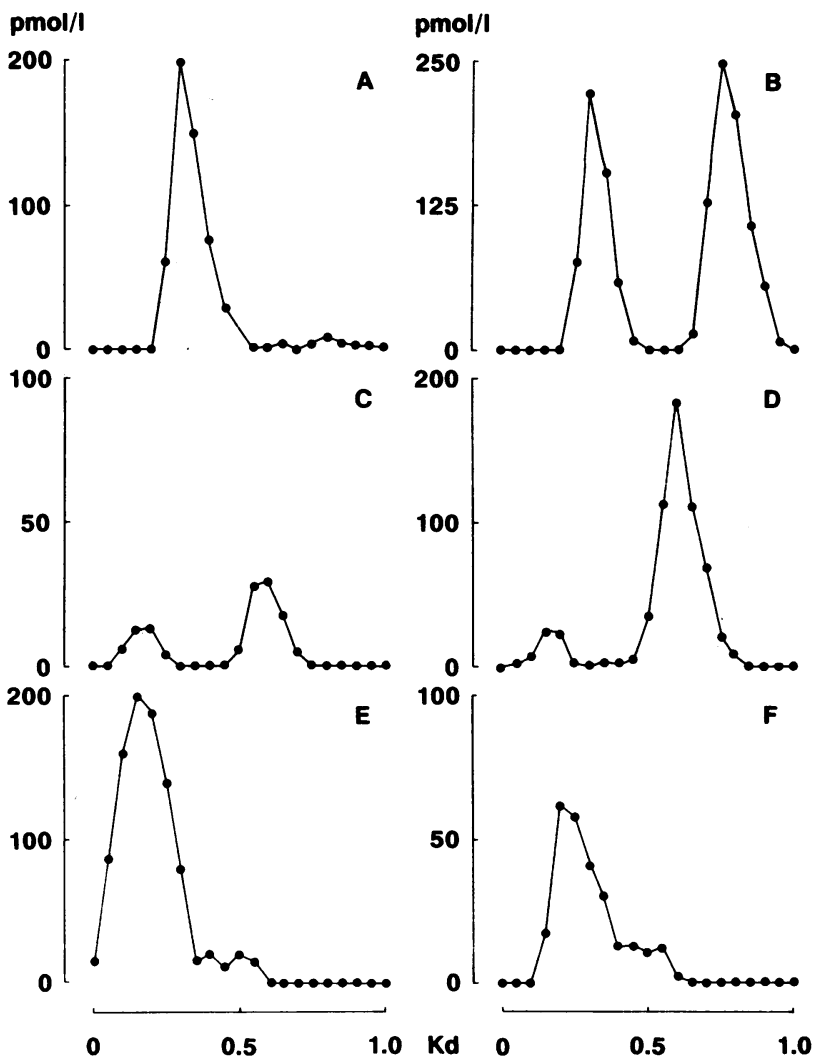

Figure 6. Results of recovery experiments of endogenous and exogenous peptides. In all panels, immunoreactivity (in picomoles per liter) is plotted against $K_{\mathrm{d}}$, the coefficient of distribution calculated as described. $(A)$ Gel filtration profile of Seppakconcentrated plasma without addition of exogenous peptides as measured with the total glucagon assay. $(B)$ Gel filtration profile of the same Seppak-treated plasma as in $A$ after addition of exogenous glucagon as measured with the total glucagon assay. Recovery of the added hormone was calculated by subtracting $A$ from $B$, and comparing the resulting amount with the applied amount. $(C) \mathrm{Gel}$ filtration profile of Seppak-treated plasma as measured with the GLP-1 assay. (D) Gel filtration profile of the same Seppak-treated plasma as $C$ plus synthetic GLP-1 (PG 78-107 amide). The recovery of added synthetic GLP-1 was calculated as above. $(E)$ Gel filtration profile of $5 \mathrm{ml}$ of plasma after addition of porcine MPGF, applied directly to the column, as measured with the GLP-1 assay. All measured concentrations were multiplied with a factor 4 to allow comparison with $F$. $(F)$ Gel filtration profile of Seppak-treated plasma representing a $20-\mathrm{ml}$ sample plus porcine MPGF (same plasma as $E$ ). 
plasma and applied directly to the gel filtration column was 77\% (Fig. 6).

GLP-1 immunoreactivity was measured in all fractions eluted from the Seppak cartridges. No immunoreactivity was eluted with water/TFA. $15 \pm 3 \%$ of the total GLP-1 immunoreactivity eluted from the cartridge was eluted with $20 \%$ acetonitrile in water, whereas $84 \pm 7 \%$ eluted with $45 \%$ acetonitrile. Nothing eluted with pure acetonitrile/TFA.

Gel filtration of crude plasma (Fig. 7). The elution positions of GLP-1 immunoreactive material were identical to those determined by gel filtrations of Seppak concentrated plasma (Fig. 5 ), but the distribution of GLP-1 immunoreactivity between the two peaks was quite different. Both in the fasting state and after intravenous arginine the main GLP-1 immunoreactive moiety eluted at $K_{\mathrm{d}} 0.15$, clearly separated from apparently immunoreactive material eluting at $V_{\mathrm{o}}$. Such interference was identified in all gel filtrations of crude plasma as measured with antiserum 2135 (Fig. 7). In the plasma drawn after the oral glucose load the $K_{\mathrm{d}} 0.15$ component was not clearly separated from the $V_{\mathrm{o}}$ interference. As shown in Fig. 8 the material eluting at $V_{\mathrm{o}}$ was completely removed by ethanol extraction.

\section{Discussion}

The aim of this study was to investigate the effects of oral glucose and intravenous arginine (known stimulants of endocrine cells of the lower gut and pancreas, respectively) on the secre-
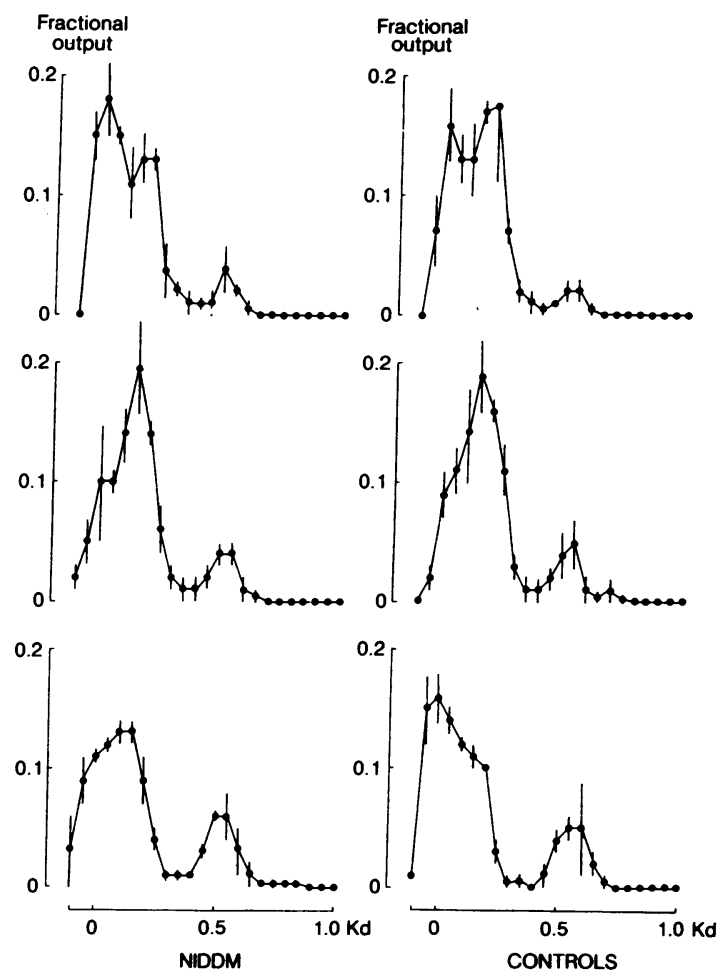

Figure 7. Gel filtration profiles of crude plasma from three NIDDM patients and three control subjects in the fasting state (top), after intravenous arginine (middle), and after oral glucose (bottom). The fractional outputs (mean \pm SEM) of GLP-1 immunoreactivity are plotted against $K_{\mathrm{d}}$, the coefficient of distribution, calculated as described. (Left panels) NIDDM patients; (right panels) control subject.

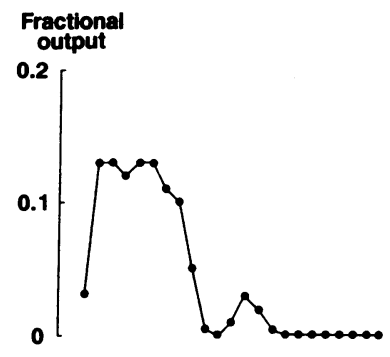

Figure 8. Gel filtration profile of a pool of plasma drawn from NIDDM subjects $30 \mathrm{~min}$ after initiation of the arginine infusion (chosen because of expected high values) without (top) and with (bottom) previous extraction with $70 \%$ ethanol, as measured with the GLP-1 radioimmunoassay employing antiserum 2135 . Fractional output is plotted against $K_{\mathrm{d}}$, the coefficient of distribution, calculated as described.

tion of products of proglucagon in man, and to characterize the secreted products using specific radioimmunoassays and chromatographic analysis. Furthermore, as both the pancreatic hormone glucagon and the gut-derived GLP-1 (PG 78-107 amide) are known to stimulate insulin secretion and thereby to influence the regulation of glucose homoeostasis, we found it interesting to study possible differences in the secretion of proglucagon products in noninsulin-dependent diabetics and in weightmatched controls.

The group of NIDDM patients was homogenous, all the patients were slightly overweight with a rather short duration of NIDDM, none had severe complications of the disease and all were treated with diet only. Furthermore, none of the patients showed hypersecretion of insulin in response to oral glucose.

We found that both intravenous arginine and oral glucose stimulate the secretion, as measured in plasma from a peripheral vein, of proglucagon products both in noninsulin-dependent diabetics and in weight-matched controls.

We also observed that the GLP-1 immunoreactivity in fasting plasma was significantly elevated in the NIDDM group compared to the control group. The concentrations of insulin and total glucagon, however, were similar in the two groups. By chromatographic analysis of Seppak-concentrated plasma we found that in the fasting state the predominating proglucagon products are enteroglucagon (human glicentin) and GLP-1 (PG 72-107 amide) judging from the elution position of these moieties.

After intravenous arginine we found increases in all peptides measured (Fig. 2). The total glucagon concentrations were similar in the two groups, whereas the concentrations of GLP-1 immunoreactivity measured were significantly higher in the NIDDM group. The integrated incremental GLP-1 responses, however, were similar in the two groups. The insulin responses to arginine in the two groups were also similar, but viewed against the higher prevailing blood glucose level, the NIDDM subjects had impaired insulin response to amino acids, as previously noted by others (19). By chromatographic analysis of plasma drawn after intravenous arginine we found that the predominating proglucagon products were, both in the NIDDM subjects and in the control subjects, judging from the Seppak concentrated plasma: glucagon; a GLP-1 immunoreac- 
tive moiety, the elution position of which corresponded exactly to that of (PG 72-107 amide) $\left(K_{d} 0.55\right)$; and a GLP-1 immunoreactive moiety eluting at $K_{\mathrm{d}} 0.15$, which probably corresponds to the MPGF, because it elutes at approximately the same position as MPGF previously identified in extracts of human and pig pancreas $(2,13)$. This elution position is also in agreement with the predicted molecular size of MPGF (4). This moiety was first identified by Patzelt et al. in biosynthetic studies of rat islets (4). By amino acid analysis the structure of MPGF was predicted to correspond to PG 72-158.

After oral glucose the plasma concentrations of all proglucagon products measured rose (except for pancreatic glucagon itself). The insulin responses to oral glucose were much lower in the NIDDM group compared with the control group. By chromatographic analysis of plasma drawn after the oral glucose we found that the predominating proglucagon products in plasma were enteroglucagon (human glicentin) and a GLP-1 immunoreactive moiety, the elution position of which corresponded exactly to that of intestinal GLP-1 (PG 87-107 amide) $\left(K_{d} 0.60\right)$. By statistical analysis, the elution positions of GLP-1 immunoreactivity was significantly different after intravenous arginine and oral glucose $\left(K_{\mathrm{d}} 0.55\right.$ vs. $\left.0.60, P<0.005\right)$.

The proglucagon products characterized by gel filtration of Seppak-concentrated plasma using the total glucagon radioimmunoassay corresponded with those identified in the venous effluent of isolated, perfused pancreas and small intestine of pigs (13): after intravenous arginine almost all immunoreactivity eluted as pancreatic glucagon, whereas after oral glucose the predominating form in plasma was enteroglucagon (human glicentin). The recoveries of total glucagon immunoreactivity after Seppak concentration and chromatography were acceptable $(>60 \%$ ). Thus, the methods employed appeared satisfactory for the analysis of these hormones.

However, the proglucagon products characterized by gel filtration of Seppak-concentrated plasma using the GLP-1 radioimmunoassay deviated from the anticipated: after oral glucose almost all GLP-1 immunoreactivity eluted at the position of intestinal GLP-1 (PG 78-107 amide), as expected (2), but both in the fasting state and after intravenous arginine the main moiety identified corresponded to PG 72-107 amide, whereas only a smaller fraction of the total GLP-1 immunoreactivity eluted at the position of MPGF. Previously, we found in gel filtrations of venous effluent, collected from the isolated, perfused porcine pancreas after intraarterial arginine infusion, that the majority of GLP-1 immunoreactivity eluted at a $K_{\mathrm{d}}$ corresponding to the MPGF (13). Similarly, by chromatographic analysis of extracts of human pancreatic tissue, both we (2) and George et al. (3) earlier found that the main GLP-1 immunoreactive form corresponded to the MPGF. Furthermore, in a preliminary study of the molecular forms of GLP-1 in fasting plasma from normals concentrated by immunoadsorption and analyzed by gel filtration we found the predominating GLP-1 immunoreactive component to correspond to the MPGF (2). In the present study the recovery of GLP-1 immunoreactivity in all gel filtrations of concentrated plasma was significantly lower than the recovery of total glucagon immunoreactivity, especially in the NIDDM group. To clarify whether the Seppak concentration procedure might affect the proportion of MPGF recovered, we applied plasma drawn in the fasting state, after intravenous arginine and oral glucose, directly onto the gel filtration columns (Fig. 7). In these gel filtrations the predominating GLP-1 immunoreactive moiety both in the fasting state and after arginine corresponded in size to MPGF. Because the chromatographic and analytical part of the two methods are identical it appears that the use of Seppak concentration causes an underestimation of the contribution of MPGF to the total plasma GLP-1 immunoreactivity. In an attempt to verify this assumption, we concentrated a $20-\mathrm{ml}$ sample of normal human plasma, containing in addition a known amount of purified porcine MPGF on Seppak cartridges as described and subjected the fraction eluted with $45 \%$ acetonitrile to gel filtration and radioimmunoassay for GLP-1 immunoreactivity as described above. The recovery of porcine MPGF employing this procedure was $36 \%$. This finding corresponds well with our data concerning the recovery of human MPGF after Seppak concentration. It should be emphasized, however, that the concentration step is very useful for the study of the smaller peptides, because their low concentration, particularly in fasting plasma, may otherwise render a chromatographic analysis impossible.

We can thus confirm that after intravenous arginine an increase in the concentration of a GLP-1 immunoreactive moiety corresponding to PG 72-107 amide ("full length GLP1") can be measured in Seppak concentrated plasma, as also noted in our previous studies (2). However, our supplementary gel filtrations of crude plasma have shown that the main GLP-1 immunoreactive moiety in plasma after intravenous arginine is the MPGF. Furthermore, we here report that the main GLP-1 immunoreactive moiety in plasma after oral glucose corresponds to PG 78-107 amide (intestinal GLP-1).

The fact that the arginine-stimulated secretion resulted in proglucagon products corresponding to those previously found in the pancreas (and not in the gut) suggests that arginine does not appreciably stimulate the intestinal proglucagon-producing cells. This is in agreement with earlier studies of enteroglucagon secretion (20). Conversely, the oral glucose only lead to increases in the concentrations of molecular forms of proglucagon that have been identified in the small intestine (but not the pancreas) suggesting that these proglucagon products were all derived from the gut. As expected, the glucagon concentrations measured with antiserum 4305 , which mainly measures glucagon of pancreatic origin, decreased during the oral glucose tolerance test. In agreement with previous observations the inhibition of pancreatic glucagon secretion was almost abolished in the diabetic subjects (21). It was not possible, however, to measure a decrease in the concentration of pancreas-derived GLP1 immunoreactive components with the present analytical technique.

Our findings of a significant correlation both between the integrated incremental pancreatic glucagon and GLP-1 responses after intravenous arginine, and between the integrated incremental total glucagon and the GLP-1 responses after oral glucose are in good agreement with this interpretation.

The time point chosen for plasma sampling for chromatographic analysis after the intravenous arginine infusion was fortunate, because all proglucagon products measured reached the highest concentrations at $30 \mathrm{~min}$. In the oral glucose experiments plasma for chromatography was drawn at $120 \mathrm{~min}$. This time point was chosen on the basis of the measurements of proglucagon products after a mixed meal, in which maximal concentrations of proglucagon products were reached at 120 min (16). After oral glucose the maximal plasma concentra- 
tions of the proglucagon products were reached earlier. The difference in GLP-1 immunoreactivity was not significant at this timepoint, as seen in Fig. 3 and in the subsequent gel filtration chromatography of the plasma pool drawn at this time (Fig. 5). However, we consider it unlikely that the gel filtration profile of the proglucagon products in plasma would differ markedly from the profile at times 30,60 , and $90 \mathrm{~min}$. After oral glucose the insulin response was much smaller in the NIDDM group compared to the control group. The incremental, integrated total glucagon and GLP-1 responses were significantly larger in the NIDDM group compared to the control group. Because diabetes and maybe insulin deficiency in particular is associated with an increased secretion of glucagon from the pancreas it might be hypothesized that a similar mechanism may affect the secretion of the intestinal endocrine cells producing proglucagon products. However, further studies will be necessary to elucidate this hypothesis.

Part of the higher concentration of GLP-1 immunoreactivity in the diabetics as compared with the controls in the fasting state and during arginine stimulation is due to major proglucagon fragment. The metabolic rate of MPGF in plasma is not known but as discussed above it is responsible for most of the GLP-1 like immunoreactivity in fasting plasma, that is with no stimulation of pancreatic proglucagon secreting cells. This might indicate that the half-life in plasma of MPGF is longer than that of the other products of proglucagon. Thus, a slight or relative hypersecretion of pancreatic proglucagon products in the NIDDM subjects combined with a fairly long half-life of MPGF might explain this finding.

During the oral glucose tolerance test there was a significant hypersecretion of GLP-1 immunoreactive material in the diabetics compared to the controls. By gel filtration analysis this hypersecretion seemed to be caused by GLP-1 (PG 78-107 amide). Though this peptide seems to be the most potent insulinotropic factor yet isolated from the gastrointestinal tract $(6$, $8-10)$ this raises the important question of the eventual role of GLP-1 in the pathogenesis of NIDDM. Clearly studies of the effect of GLP-1 on insulin secretion in diabetics are now needed.

\section{Acknowledgments}

Lisbet Mardrup is thanked for excellent technical assistance.

This work was supported by the Lundbeck Foundation (grant to C. Ørskov), the Danish Medical Research Council, and the Novo Foundation.

\section{References}

1. Bell, G. I., R. Sanchez-Pescador, P. J. Laybourn, and R. C. Najarian. 1983. Exon duplication and divergence in the human proproglucagon gene. Nature (Lond.). 304:368-371.

2. Ørskov, C., J. J. Holst, S. S. Poulsen, and P. Kirkegaard. 1987. Pancreatic and intestinal processing of proglucagon in man. Diabetologia. 30:874-881.

3. George, S. K., L. O. Uttenthal, M. Ghiglione, and S. R. Bloom. 1985. Molecular forms of glucagon-like peptides in man. FEBS (Fed. Eur. Biochem. Soc.) Lett. 192:275-278.

4. Patzelt, C., and E. Schiltz. 1984. Conversion of proglucagon in pancreatic alpha cells: the major end products are glucagon and a single peptide, the major proglucagon fragment, that contains two glucagon-like sequences. Proc. Natl. Acad. Sci. USA. 81:5007-5011.

5. Thim, L., and A. J. Moody. 1981. The primary structure of porcine glicentin (proglucagon). Regul. Pept. 2:139-141.

6. Ørskov, C., M. Bersani, A. H. Johnsen, P. Højrup, and J. J. Holst. 1989. Complete sequences of glucagon-like peptide-1 from human and pig small intestine. J. Biol. Chem. 264:12826-12829.

7. Buhl, T., L. Thim, H. Kofod, C. Ørskov, H. Harling, and J. J. Holst. 1988. Naturally occurring products of proglucagon $111-160$ in the porcine and human small intestine. J. Biol. Chem. 263:8621-8624.

8. Holst, J. J., C. Ørskov, O. V. Nielsen, and T. W. Schwartz. 1987. Truncated glucagon-like peptide-1, an insulin-releasing hormone from the distal gut. FEBS (Fed. Eur. Biochem. Soc.) Lett. 211:169-174.

9. Mojsov, S., G. C. Weir, and J. F. Habener. 1987. Insulinotropin: glucagonlike peptide-1 release in the perfused rat pancreas. J. Clin. Invest. 79:616-619.

10. Kreymann, B., G. Williams, M. A. Ghatei, and S. R. Bloom. 1987. Glucagon-like peptide-1 7-36: a physiological incretin in man. Lancet. ii:1300-1303.

11. Weir, G. C., S. Mojsov, G. C. Hendrick, and J. F. Habener. 1989. Glucagonlike peptide-I (7-37) actions on endocrine pancreas. Diabetes. 38:338-342.

12. Ørskov, C., J. J. Holst, and O. V. Nielsen. 1988. Effect of truncated glucagon-like peptide-1 (proglucagon 78-107 amide) on endocrine secretion from pig pancreas, antrum and non-antral stomach. Endocrinology. 123:2009-2013.

13. Orskov, C., J. J. Holst, S. Knuhtsen, F. G. A. Baldissera, S. S. Poulsen, and O. V. Nielsen. 1986. Glucagon-like peptides GLP-1 and GLP-2, predicted products of the glucagon gene, are secreted separately from pig small intestine but not pancreas. Endocrinology. 119:1467-1475.

14. Holst, J. J. 1980. Evidence that glicentin contains the entire sequence of glucagon. Biochem. J. 187:337-343.

15. Holst, J. J. 1982. Evidence that enteroglucagon(II) is identical with the C-terminal sequence (residues 33-69) of glicentin. Biochem. J. 207:381-388.

16. Orskov, C., and J. J. Holst. 1987. Radioimmunoassays for glucagon-like peptides 1 and 2 (GLP-1 and GLP-2). Scand. J. Clin. Lab. Invest. 47:165-174.

17. Albano, J. D. M., R. P. Ekins, G. Maritz, and R. C. Turner. 1972. A sensitive precise radioimmunoassay of serum insulin relying on charcoal separation of bound and free hormone moieties. Acta Endocrinol. 70:487-509.

18. Heding, L. G. 1971. Radioimmunological determination of pancreatic and gut glucagon in plasma. Diabetologia. 7:10-19.

19. Ward, W. K., D. C. Bolgiano, B. McNight, J. B. Halter, and D. Porte, Jr. 1984. Diminished B cell secretory capacity in patients with non-insulin dependent diabetes mellitus. J. Clin. Invest. 74:1318-1328.

20. Kåresen, R., B. Tronier, and S. Aune. 1980. Immunoreactive glucagon and insulin C-peptide in man after resection of the pancreas and total pancreatectomy. Am. J. Surgery. 140:272-276.

21. Unger, R., E. Aguilar-Parada, W. Muller, and A. Eisentraut. 1972. Studies of pancreatic alpha cell function in normal and diabetic subjects. J. Clin. Invest. 49:837-848. 